\title{
How a Mycoparasite Employs G-Protein Signaling: Using the Example of Trichoderma
}

\author{
Markus Omann and Susanne Zeilinger \\ Research Area of Gene Technology and Applied Biochemistry, Working Group Molecular Biochemistry of Fungi, \\ Institute for Chemical Engineering, Vienna University of Technology, Getreidemarkt 9, 1060 Vienna, Austria \\ Correspondence should be addressed to Markus Omann, omann@mail.tuwien.ac.at
}

Received 20 May 2010; Revised 6 July 2010; Accepted 20 July 2010

Academic Editor: Terry Hebert

Copyright ( 2010 M. Omann and S. Zeilinger. This is an open access article distributed under the Creative Commons Attribution License, which permits unrestricted use, distribution, and reproduction in any medium, provided the original work is properly cited.

\begin{abstract}
Mycoparasitic Trichoderma spp. act as potent biocontrol agents against a number of plant pathogenic fungi, whereupon the mycoparasitic attack includes host recognition followed by infection structure formation and secretion of lytic enzymes and antifungal metabolites leading to the host's death. Host-derived signals are suggested to be recognized by receptors located on the mycoparasite's cell surface eliciting an internal signal transduction cascade which results in the transcription of mycoparasitismrelevant genes. Heterotrimeric $G$ proteins of fungi transmit signals originating from G-protein-coupled receptors mainly to the cAMP and the MAP kinase pathways resulting in regulation of downstream effectors. Components of the G-protein signaling machinery such as $\mathrm{G} \alpha$ subunits and G-protein-coupled receptors were recently shown to play crucial roles in Trichoderma mycoparasitism as they govern processes such as the production of extracellular cell wall lytic enzymes, the secretion of antifungal metabolites, and the formation of infection structures.
\end{abstract}

\section{Introduction}

All living organisms are confronted with a plethora of different stimuli due to exposure to the environment. Recognition of these stimuli and appropriate cellular responses like induction of gene transcription and protein phosphorylation are crucial for survival. Sensed at the cells surface these signals are mediated to intracellular elicitors by transmembrane signaling pathways. Fungi in particular emit sex-specific pheromones to attract potential mating partners of the opposite mating type. Surviving of pathogenic and mycoparasitic fungi depends on host-derived signals allowing them to recognize their hosts $[1,2]$.

For more than 70 years, species of the filamentous fungus Trichoderma have been known to be able to attack and metabolize plant pathogenic fungi, and therefore they are used as biocontrol agents [3]. Currently Trichoderma-based biological pesticides (e.g., SoilGard, Trichodex) are applied against a variety of plant pathogenic fungi like Rhizoctonia solani, Botrytis cinerea, Sclerotium rolfsii, Sclerotinia sclerotiorum, and Fusarium spp. [4-6].

Biocontrol is defined as a number of different mechanisms working synergistically to achieve disease control revealing complex interactions between biological control agents, plant pathogen, and plant [7]. These mechanisms could be either indirect like competition for nutrients and space, antibiosis and stimulation of plant-defense mechanisms, or direct like mycoparasitism [2].

Trichoderma spp. exhibit the ability to survive under unfavorable conditions predominating in ecological niches like salt marshes. Strains used in biological control should stand a wide range of temperatures, salinity, low moisture and show resistance to fungicides and chemicals used in soil treatment. These characteristics, together with their ability to produce highly efficient siderophores which chelate iron resulting in growth inhibition of other fungi make Trichoderma potent competitors [8-10]. For stimulation of plant-defense mechanisms Trichoderma produces proteins 
and low-molecular-weight compounds which prevent the plant from further infections [11]. Furthermore, Trichoderma secretes diverse secondary metabolites like pyrones, peptaibols, and terpenes, which can inhibit growth of plant pathogenic fungi [6].

Fungal mycoparasitism, the direct attack of one fungus on another, implies different processes occurring consecutively. These processes include recognition of the host, formation of morphological changes such as coiling around the host's hyphae and development of appressorium-like structures and subsequent penetration and killing of the host $[2,12,13]$. For penetration of the host's cell wall Trichoderma produces hydrolytic enzymes like chitinases, glucanases, and proteases [14]. To some extent production of these enzymes is already induced prior to physical contact with the host due to inducing diffusible host-derived factors $[15,16]$. In addition, complementary molecules present at the surface of both the host and the mycoparasite can mediate physical contact [17]. The plant pathogen $R$. solani was shown to possess glycoproteins (lectins) on its surface which are able to agglutinate carbohydrate moieties present on Trichoderma hyphae [12] and thus trigger coiling of the mycoparasite around the host hyphae $[4,18]$.

For the activation of the mycoparasitic response, a model of different signaling pathways responding to multiple signals from the host can be assumed. This is based on findings that on the one hand lectins induce morphological changes like coiling around the host hyphae and appressorium development in Trichoderma even though they are ineffective inducers of the chitinolytic enzyme system. On the other hand cell wall degradation products are powerful inducers of chitinase production whereas they do not efficiently induce coiling. Furthermore lectins induce coiling only upon physical contact while parts of the chitinolytic enzyme system are already induced before direct contact between Trichoderma and its host.

Receptor molecules, located within the mycoparasite's cell membrane, are supposed to be the linkage between these host-derived signals and intracellular signalling pathways of Trichoderma resulting in, for example, the activation of mycoparasitism-relevant genes. Recently, examination of these intracellular signaling pathways of Trichoderma began and revealed that G-protein signaling plays an important role in mycoparasitism [19-23].

\section{G-Protein Signaling}

2.1. Components of G-Protein Signaling in Fungi. Classical G-proteins are heterotrimers composed of three subunits termed $\mathrm{G} \alpha, \mathrm{G} \beta$, and $\mathrm{G} \gamma$, which are highly conserved from fungi to humans. In fungi, heterotrimeric $G$ proteins play essential roles in sexual and pathogenic development, in secondary metabolism, in pheromone signaling cascades and processes determining fungal virulence $[1,24]$.

Fungal $\mathrm{G} \alpha$ subunits can be divided into three major subgroups according to a phylogenetic tree generated by multiple alignment of fungal G-protein sequences. Subgroup I $\mathrm{G} \alpha$ proteins are homologs of the mammalian $\mathrm{G} \alpha \alpha_{i}$ subunit as both contain a consensus sequence for myristoylation (MGXXXS) at the N-terminus [25] and a site for ADPribosylation by pertussis toxin $(\mathrm{CAAX})$ at the $\mathrm{C}$-terminus [26]. G $\alpha$ proteins of subgroup I lower the intracellular cAMP level by inhibiting adenylyl cyclase [27]. Among subgroup II members, protein sequences are not as well conserved as of members of groups I or III [28]. Their functions are less obvious, and their direct effectors still remain to be identified [24]. Members of subgroup III posses a myristoylation site at the N-terminus and positively influence the intracellular cAMP level. In analogy to the mammalian $\mathrm{G} \alpha$ s family, members of subgroup III have been designated as adenylyl cyclase stimulating fungal $\mathrm{G} \alpha$ s subunits [1].

Most fungal species possess one representative of each $\mathrm{G} \alpha$ subgroup. However, screening the whole genome of Saccharomyces cerevisiae revealed that GPA1 and GPA2 are the only two $\mathrm{G} \alpha$ subunit-encoding genes in this organism and they cannot be placed unambiguously into one of the three subgroups described above. GPA1 shows sequence relationship to subgroup I but lacks the consensus site for pertussis toxin-dependent ribosylation $[1,29]$.

By screening the genomes of Ustilago maydis and Aspergillus oryzae, a fourth $\mathrm{G} \alpha$ subunit has been identified in these fungi. Both, Gpa4 of U. maydis and GaoC of A. oryzae, exhibit some unusual features and therefore do not belong to one of the three subgroups described above. Phylogenetic analysis indicated that Gpa4 and GaoC are distinct thus excluding the presence of a conserved fourth class of $\mathrm{G} \alpha$ subunits in fungi $[30,31]$.

Fungal $\mathrm{G} \beta$-encoding genes were shown to affect the sexual and asexual life cycle of these organisms [32]. In addition, examination of $\mathrm{G} \beta$ in the model filamentous fungus Neurospora crassa suggested that this subunit is also essential for the complex formation and stability of $\mathrm{G} \alpha$ and Gy [33]. Gy subunits form a large family of small proteins from which the majority of filamentous fungi possess only a single conserved member [32]. G $\gamma$ deletion in $N$. crassa for instance led to the same phenotype as deletion of the $\mathrm{G} \beta$ subunit such as increased conidiation, female-sterility, and decreased intracellular cAMP levels, and in addition an altered concentration of the three $\mathrm{G} \alpha$ proteins [33].

In fungi, G-protein signaling pathways elicit cellular responses like mating, cell division, growth, morphogenesis, and pathogenic development [34] but up to now only little information is available on the characteristics and functions of fungal G-protein-coupled receptors (GPCRs). Numerous fungal genomes are sequenced nowadays and comparative genomics resulted in the classification of fungal GPCRs intofor example, nine classes [31]: classes I and II include pheromone receptors related to $S$. cerevisiae Ste2p and Ste3p receptors; classes III and V consist of putative carbon source and cAMP sensors; class IV contains Schizosaccharomyces pombe Stm1p-like nitrogen sensors; class VI comprises a unique class in filamentous fungi representing GPCRs with an RGS domain in the cytoplasmatic moiety of the protein; members of classes VII and VIII share similarities with the rat growth hormone releasing factor (class VII) and the steroid receptor $\mathrm{mPR}$ (class VIII); and class IX contains fungal opsins similar to the bacterial retinal-binding rhodopsin with 
the well-characterized representatives NOP-1 and ORP-2 of $N$. crassa [35]. Subsequent to the release of the genome of the rice blast fungus Magnaporthe grisea, a large novel class of fungal GPCRs related to PTH11, a receptor required for the development of the appressorium, was defined [36, 37] and recently Zheng et al. [38] reported on the identification of three novel classes, each of which comprises one member in the plant pathogen Verticillium spp. with high sequence similarity to GPCRs of higher eukaryotes.

\subsection{Regulation of G-Protein Signaling in Fungi. Activa-} tion/deactivation and the intensity of G-protein signaling are regulated by interactions of the $\mathrm{G} \alpha$ subunit with GPCRs, G $\beta \gamma$ subunits, GTPase-activating, and multiple other proteins $[39,40]$.

GTPase-activating proteins, such as RGS (regulator of G-protein signaling) proteins, act to accelerate hydrolysis of GTP to GDP on G $\alpha$ subunits and thereby terminate the transduced signal $[39,41]$. While in $S$. cerevisiae the RGS protein Sst2 was found to control mating responses by promoting the hydrolysis of GTP on the G $\alpha$ subunit Gpa1 via binding to the Ste2 pheromone receptor [42], Rgs2, the second RGS protein of yeast, negatively regulates the $\mathrm{Gpa} 2 \mathrm{G} \alpha$ subunit and glucose signaling via the Gpr1 GPCR [43]. The filamentous model fungus Aspergillus nidulans contains four RGS proteins (in addition to the RGS domaincontaining GPCR GprK; [31]) among which FlbA and RgsA were shown to negatively regulate the subgroup I and III $\mathrm{G} \alpha$ subunits FadA and $\mathrm{GanB}$, respectively $[44,45]$. In pathogenic fungi such as Cryphonectria parasitica, M. grisea, Cryptococcus neoformans, and Metarhizium anisopliae, RGS proteins were described to regulate $\mathrm{G} \alpha$-mediated signaling of fungal virulence [46-50].

Modulation of the activity of $\mathrm{G} \beta \gamma$ subunits can be achieved by proteins belonging to the family of phosducins or phosducin-like proteins. Reports on the function of these proteins in filamentous fungi are rare. In A. nidulans and the chestnut blight fungus $C$. parasitica, the phosducin-like proteins PhnA and BDM-1, respectively, were shown to be necessary for $\mathrm{G} \beta$ function $[51,52]$. In addition, BDM-1 was recently reported to be a phosphoprotein and it was shown to play a positive role in regulation of virulence [53].

In addition to regulatory proteins influencing G-protein activity, mechanisms directly regulating the activation and stability of GPCRs exist. Although, there are not yet any reports on their mode of action in filamentous fungi, regulation of the Ste 2 and Ste 3 pheromone receptors has been studied in detail in the model organism S. cerevisiae. GPCR signaling was shown to be regulated by ligandtriggered Ste 2 receptor oligomerization and phosphorylation resulting in receptor desentization, endocytosis, and internalization [54-56]. Like Ste2, Ste3 can be recycled via ligand dependent manner [57]. In addition, the Afr 1 protein was found to prevent G-protein activation via the Ste2 receptor independent of receptor phosphorylation and endocytosis [58] whereas the Asg7 protein inhibits signaling by G $\beta \gamma$ via a concerted action with the Ste3 pheromone receptor [59].

\section{The Role of G-Protein Signaling in Trichoderma Mycoparasitism}

Comparable to fungal pathogens which attack plant, animal or human hosts, mycoparasites are pathogenic to other fungi. The mycoparasitic attack involves similar processes as those described for other pathogenic fungi such as infection-related morphogenesis, the production of hydrolytic enzymes involved in host invasion, and mycotoxin synthesis.

In plant pathogenic fungi, subgroup I and III $\mathrm{G} \alpha$ proteins and the cAMP pathway were repeatedly shown to play an essential role in regulating virulence-associated processes such as filamentation and appressorium formation. Similarly, G-protein signaling also governs pathogenesis and the production of virulence factors in various fungal human pathogens such as C. neoformans and Aspergillus fumigatus (reviewed in [24]).

Investigating different Trichoderma spp. for G-protein signaling compounds revealed that they have members of fungal $\mathrm{G} \alpha$ subgroups I, II, and III (Figure 1). RochaRamírez et al. [19] silenced and overexpressed tga1, encoding the subgroup I $\mathrm{G} \alpha$ subunit in T. atroviride strain IMI 206040. Silencing of $\operatorname{tgal}$ led to intense sporulation and slowly growing colonies whereas overexpression had the opposite effect by promoting vegetative proliferation and increased coiling, a morphological change associated with the mycoparasitic host attack. In direct plate confrontation assays with $R$. solani as the host fungus, the transformed lines overexpressing tgal showed an impressive increase in the capacity of the fungus to overgrow and parasitize the host compared to the parental strain. On the other hand, lines blocked in the production of Tgal were unable to overgrow the host [19].

A more profound functional characterization of Tgal was performed by Reithner et al. [21], who extended the involvement of this G-protein $\alpha$ subunit to the production of antifungal metabolites and the formation of extracellular chitinases both processes relevant for the mycoparasitic host attack. tgal knockout mutants showed strongly reduced extracellular chitinase activities and a decreased transcription of the chitinase-encoding genes nag1 (Nacetyl-glucosaminidase-encoding) and ech42 (endochitinase 42-encoding). Investigation of the antifungal activity of the $\Delta$ tgal mutant revealed reduced amounts of the major antifungal metabolite of $T$. atroviride, 6-pentyl- $\alpha$-pyrone [21], while elevated amounts of peptaibols, peptides with antibiotic activity, could be detected [60]. These results indicate contrasting functions of Tgal in regulating the biosynthesis of different antifungal metabolites. An elevated internal steady-state cAMP level in the $\Delta$ tgal mutants compared to the parental strain confirmed that Tgal represents a member of the adenylyl cylcase inhibiting subgroup I of fungal $\mathrm{G} \alpha$ subunits [21].

Contrary to T. atroviride Tga1, its homologue TgaA does not influence growth or conidiation in T. virens, another mycoparasitic Trichoderma species. In antagonistic assays, when Trichoderma is confronted with a host fungus in a dual plate culture, $T$. virens $\triangle \operatorname{tga} A$ mutants showed a 


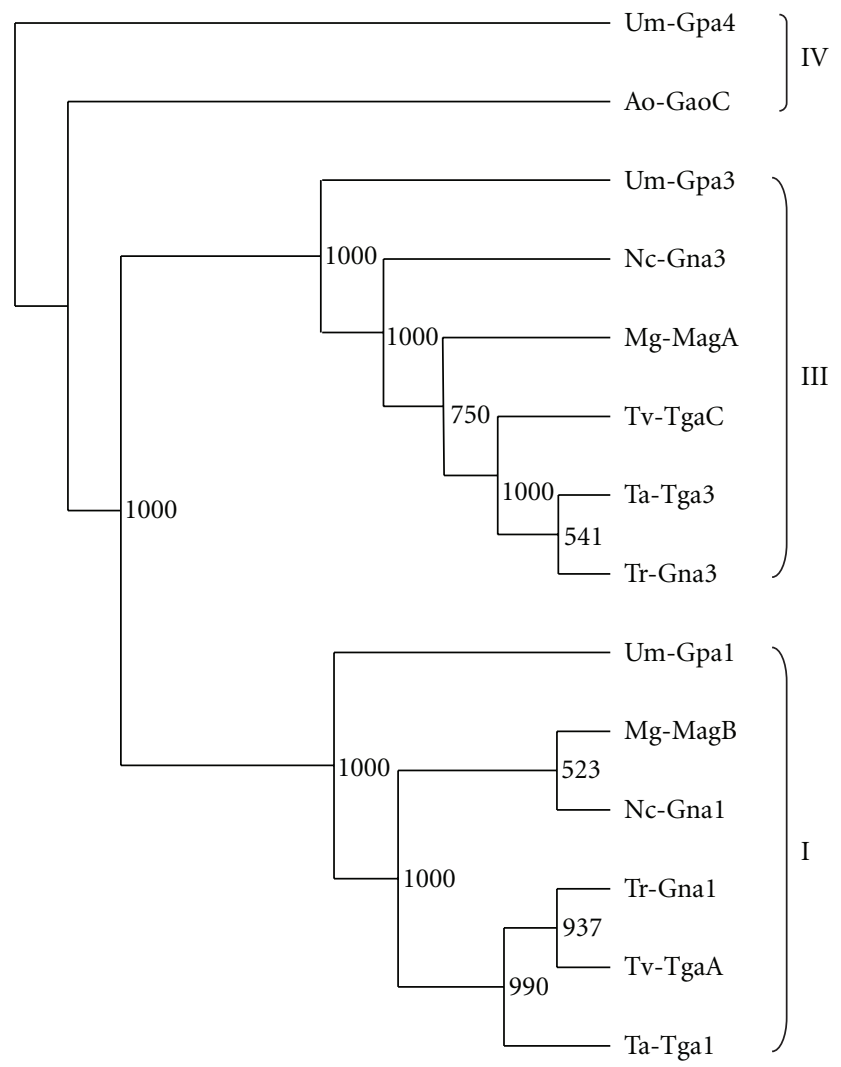

FIGURE 1: Relationship of fungal $\mathrm{G} \alpha$ amino acid sequences of subgroups I and III whose members Tgal and Tga3 were shown to be essential for mycoparasitism of T. atroviride. In addition, the fourth $\mathrm{G} \alpha$ subunit only present in U. maydis (Gpa4) and A. oryzae (GaoC) were included and are indicated as subgroup IV. The tree was generated using Neighbor-Joining algorithm subsequent to CLUSTALX alignment. The fourth $\mathrm{G} \alpha$ subunit of $U$. maydis $\mathrm{Gpa} 4$ has been defined as outgroup. Abbreviations used: Ao: Aspergillus oryzae; Mg: Magnaporthe grisea; Nc: Neurospora crassa; Ta: Trichoderma atroviride; Tr: Trichoderma reesei; Tv: Trichoderma virens; Um: Ustilago maydis.

host-specific behavior as they could hardly colonise sclerotia of the plant pathogenic fungus $S$. rolfsii whereas they were fully pathogenic against another plant pathogen, $R$. solani. T. virens $\triangle \operatorname{tgaB}$ mutants missing the subgroup II $\mathrm{G} \alpha$ protein revealed unaltered growth, sporulation, and mycoparasitism of R. solani and sclerotia of S. sclerotiorum [20].

Functional characterization of the subgroup III $\mathrm{G} \alpha$ protein Tga3 of T. atroviride revealed its involvement in regulating vegetative growth and conidiation. $\Delta$ tga3 knockout mutants exhibited significantly reduced intracellular cAMP levels compared to the parental strain [22]. Accordingly, examination of a gna3QL mutant of the only weakly mycoparasitic species $T$. reesei, carrying a constitutively activated allele of the subgroup III G $\alpha$ protein-encoding tga 3 homologue gna3, revealed a severe increase in intracellular cAMP levels $[23,61]$. This confirmed the stimulatory role of the subgroup III $\mathrm{G} \alpha$ proteins Tga3 and Gna3 on the activity of adenylyl cyclase.

Analysis of the mycoparasitic activity of $T$. atroviride $\Delta$ tga 3 mutants in antagonistic plate assays revealed that they were completely avirulent, that is, they lost the ability to attack and lyse host fungi [22]. Microscopic characterization showed that the mutants were unable to form mycoparasitism-related infection structures, like attachment to and coiling around the host hyphae. Interestingly, addition of $5 \mathrm{mM}$ exogenous cAMP to the confrontation assays led to a restoration of infection structure formation. When analyzing the production of cell wall lytic enzymes in $\Delta$ tga3 knockout mutants, it turned out that Tga3 is also involved in regulating this mycoparasitism-relevant process. The mutants exhibited reduced levels of extracellularly secreted chitinases compared to the parental strain although they showed elevated transcription of the chitinase-encoding genes nag1 and ech42. Further experiments revealed that chitinolytic enzymes are retained inside the cell suggesting an influence of Tga3 on chitinase gene transcription and secretion [22]. In gna3QL mutants of T. reesei elevated levels of different extracellular enzymes like endochitinase, $\mathrm{N}$-acetylglucosaminidase, $\beta$-1,3-glucanase, lipase, and phosphatase were found [23]. In addition, the gna3QL mutants exhibited a significantly increased transcript abundance of the major cellulase-encoding gene $c b h 1$ compared to the parental strain when the fungus was cultivated in the presence of light [61]. The authors attribute this raise in enzyme production to the elevated intracellular cAMP levels caused by the constitutively activated Gna3 protein. 


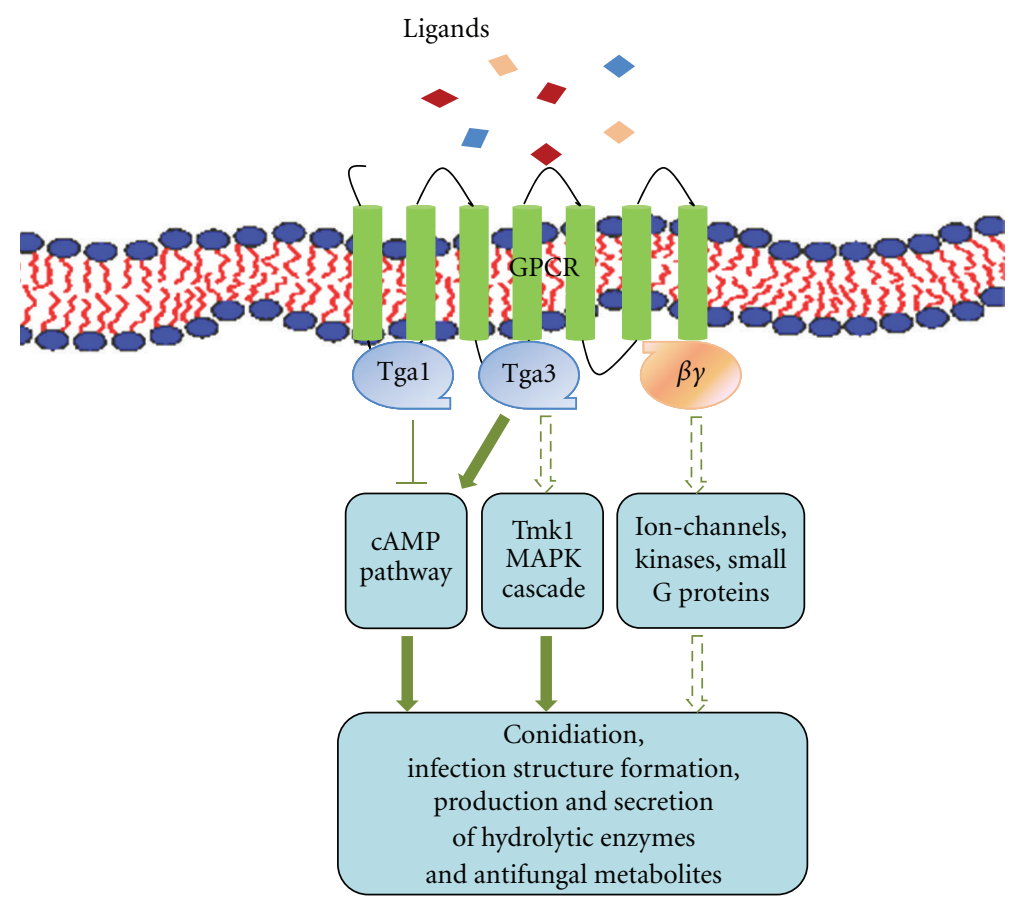

FIGURE 2: Schematic illustration of G-protein signaling in Trichoderma atroviride. GPCR: G protein-coupled receptor; Tga1, Tga3: subgroup I and III G-protein $\alpha$ subunits; Tmk1: MAP kinase.

In addition to regulating infection structure formation and the production of cell-wall-degrading enzymes such as chitinases, T. atroviride Tga 3 was also found to be required for the production of antifungal metabolites [22]. While there is a clear correlation between sporulation of the fungus and the secretion of antifungal metabolites in the $T$. atroviride parental strain, $\Delta$ tga 3 mutants were fully impaired in the production of peptaibols although they exhibited a hypersporulating phenotype [62].

Interestingly, the Tmk1 MAP kinase was found to regulate the expression of chitinase-encoding genes in $T$. atroviride in a way similar to the Tga $3 \mathrm{G} \alpha$ protein [63]. This suggests that a MAPK cascade involving Tmk1 acts downstream of Tga3 in governing chitinase production.

The crucial roles of the subgroup I and III G $\alpha$ proteins in regulating mycoparasitism-relevant processes implicates that identifying and clarifying the role of the corresponding G-protein-coupled receptors will be a fundamental step toward understanding the processes of host recognition and activation of the attack of phytopathogenic host fungi by mycoparasitic Trichoderma species.

Recently, analysis of GPCRs in Trichoderma started and resulted in the in silico identification of more than 50 such receptors in the genome of both T. reesei $[64]$ as well as the mycoparasitic species T. atroviride and T. virens (S. Zeilinger, M. Omann, unpublished). Based on this analysis, four GPCR-encoding genes from the mycoparasite $T$. atroviride were isolated and further characterized. The obtained results showed that at least the Gprl receptor, grouping to the class of cAMP receptor-like (CRL) proteins (class $\mathrm{V}$ of fungal GPCRs), plays a major role during vegetative growth and conidiation in T. atroviride [64].
Furthermore, mutants bearing a gpr1 gene whose expression is silenced by an RNAi approach, showed a complete loss of mycoparasitism accompanied by a failure to attach to and coil around host hyphae. Interestingly, this defect in host recognition and infection structure formation could be restored by addition of exogenous cAMP [65] — similar to what was found for T. atroviride $\Delta$ tga3 mutants [22]. These results suggest that Gprl regulates infection structure formation via the cAMP-pathway by signaling via the Tga3 $\mathrm{G} \alpha$ protein.

\section{Conclusions}

Mycoparasitism comprises the interaction between two fungi involving an elaborate cross-talk of the host and the pathogen. During recent years, an increasing number of studies on the signaling pathways participating in this interaction have been performed and revealed high conservation of the investigated compounds from mycoparasitic Trichoderma to homologous proteins from other fungi.

Accordingly, signaling pathways employing, for example, $\mathrm{G} \alpha$ subunits of heterotrimeric $\mathrm{G}$ proteins, mitogen-activated protein kinases, adenylyl cyclases, and G-protein-coupled receptors have been shown to be important for virulence in fungi being pathogenic to plants animals/humans, as well as mycoparasites.

In mycoparasitic Trichoderma species, both subgroup I and subgroup III $G \alpha$ proteins were shown to govern mycoparasitism-relevant processes such as the production of cell wall lytic enzymes and antifungal metabolites and the formation of infection structures. Both subgroup I and III $\mathrm{G} \alpha$ proteins of T. atroviride signal—at least partially—via the 
cAMP pathway as Tgal was proven to negatively influence the activity of adenylate cyclase whereas Tga3 stimulated its activity (Figure 2).

The essential role of G-protein signaling in activation of the mycoparasitic response of Trichoderma was further supported by the functional characterization of $T$. atroviride Gpr1. Similar to the Tga3 G $\alpha$ subunit, the Gpr1 G-proteincoupled receptor seems to be involved in recognizing hostderived signals and transducing them via the cAMP pathway. Gprl, therefore, is the first GPCR from a mycoparasitic fungus which was functionally characterized and the first 7-transmembrane receptor belonging to the CRL class of fungal GPCRs for which pathogenicity-related functions could be shown.

Although during recent years there has been considerable progress in elucidating G-protein-mediated signaling in pathogenic fungi, there are still many unsolved questions especially concerning host recognition and regulation of signaling events. The elucidation of these processes will for sure be highly beneficial not only for developing mechanisms and substances for combating these pathogens, but also for a better understanding of the molecular processes underlying fungal mycoparasitism.

\section{Acknowledgements}

The described work performed by the authors on T. atroviride signal transduction was supported by Grants from the Fonds zur Förderung Wissenschaftlicher Forschung (FWF P15483 and P18109). S Zeilinger is recipient of an EliseRichter fellowship (V139-B20) funded by FWF.

\section{References}

[1] M. Bölker, "Sex and crime: heterotrimeric G proteins in fungal mating and pathogenesis," Fungal Genetics and Biology, vol. 25, no. 3, pp. 143-156, 1998.

[2] T. Benítez, A. M. Rincón, M. C. Limón, and A. C. Codón, "Biocontrol mechanisms of Trichoderma strains," International Microbiology, vol. 7, no. 4, pp. 249-260, 2004.

[3] R. Weindling, "Trichoderma lignorum as a parasite of other soil fungi," Journal of Phytopathology, vol. 22, pp. 837-845, 1932.

[4] R. Barak and I. Chet, "Determination, by fluorescein diacetate staining, of fungal viability during mycoparasitism," Soil Biology and Biochemistry, vol. 18, no. 3, pp. 315-319, 1986.

[5] I. Chet, "Trichoderma-application, mode of action, and potential as a biocontrol agent of soilborne plant pathogenic fungi," in Innovative Approaches to Plant Disease Control, pp. 137-160, John Wiley \& Sons, New York, NY, USA, 1987.

[6] L. Hjeljord and A. Tronsmo, "Trichoderma and Gliocladium in biological control: an overview," in Trichoderma and Gliocladium, G. E. Harman and C. P. Kubicek, Eds., vol. 2, pp. 131-152, Taylor and Francis, London, UK, 1998.

[7] C. R. Howell, "Mechanisms employed by Trichoderma species in the biological control of plant diseases: the history and evolution of current concepts," Plant Disease, vol. 87, no. 1, pp. 4-10, 2003.

[8] D. Klein and D. E. Eveleigh, "Ecology of Trichoderma," in Trichoderma and Gliocladium, C. P. Kubicek and G. E. Harman, Eds., vol. 1, pp. 57-74, Taylor and Francis, London, UK, 1998.
[9] I. Chet and J. Inbar, "Biological control of fungal pathogens," Applied Biochemistry and Biotechnology, vol. 48, no. 1, pp. 3743, 1994.

[10] M. Eisendle, H. Oberegger, R. Buttinger, P. Illmer, and H. Haas, "Biosynthesis and uptake of siderophores is controlled by the PacC-mediated ambient-pH regulatory system in Aspergillus nidulans," Eukaryotic Cell, vol. 3, no. 2, pp. 561563, 2004.

[11] G. E. Harman, C. R. Howell, A. Viterbo, I. Chet, and M. Lorito, "Trichoderma species-opportunistic, avirulent plant symbionts," Nature Reviews Microbiology, vol. 2, no. 1, pp. 4356,2004

[12] Y. Elad, R. Barak, and I. Chet, "Possible role of lectins in mycoparasitism," Journal of Bacteriology, vol. 154, no. 3, pp. 1431-1435, 1983.

[13] Z. Lu, R. Tombolini, S. Woo, S. Zeilinger, M. Lorito, and J. K. Jansson, "In vivo study of Trichoderma-pathogen-plant interactions, using constitutive and inducible green fluorescent protein reporter systems," Applied and Environmental Microbiology, vol. 70, no. 5, pp. 3073-3081, 2004.

[14] Y. Elad, I. Chet, and Y. Henis, "Degradation of plant pathogenic fungi by Trichoderma harzianum," Canadian Journal of Microbiology, vol. 28, pp. 719-725, 1982.

[15] C. Cortes, A. Gutierrez, V. Olmedo, J. Inbar, I. Chet, and A. Herrera-Estrella, "The expression of genes involved in parasitism by Trichoderma harzianum is triggered by a diffusible factor," Molecular and General Genetics, vol. 260, no. 2-3, pp. 218-225, 1998.

[16] S. Zeilinger, C. Galhaup, K. Payer et al., "Chitinase gene expression during mycoparasitic interaction of Trichoderma harzianum with its host," Fungal Genetics and Biology, vol. 26, no. 2, pp. 131-140, 1999.

[17] S. H. Barondes, "Lectins: their multiple endogenous cellular functions," Annual Review of Biochemistry, vol. 50, pp. 207$231,1981$.

[18] J. Inbar and L. Chet, "A newly isolated lectin from the plant pathogenic fungus Sclerotium rolfsii: purification, characterization and role in mycoparasitism," Microbiology, vol. 140, no. 3, pp. 651-657, 1994.

[19] V. Rocha-Ramírez, C. Omero, I. Chet, B. A. Horwitz, and A. Herrera-Estrella, "Trichoderma atroviride G-protein $\alpha$ subunit gene tgal is involved in mycoparasitic coiling and conidiation," Eukaryotic Cell, vol. 1, no. 4, pp. 594-605, 2002.

[20] P. K. Mukherjee, J. Latha, R. Hadar, and B. A. Horwitz, "Role of two G-protein alpha subunits, TgaA and TgaB, in the antagonism of plant pathogens by Trichoderma virens," Applied and Environmental Microbiology, vol. 70, no. 1, pp. 542-549, 2004.

[21] B. Reithner, K. Brunner, R. Schuhmacher et al., "The G protein $\alpha$ subunit Tgal of Trichoderma atroviride is involved in chitinase formation and differential production of antifungal metabolites," Fungal Genetics and Biology, vol. 42, no. 9, pp. 749-760, 2005.

[22] S. Zeilinger, B. Reithner, V. Scala, I. Peissl, M. Lorito, and R. L. Mach, "Signal transduction by Tga3, a novel G protein $\alpha$ subunit of Trichoderma atroviride," Applied and Environmental Microbiology, vol. 71, no. 3, pp. 1591-1597, 2005.

[23] R. do Nascimento Silva, A. S. Steindorff, C. J. Ulhoa, and C. R. Félix, "Involvement of G-alpha protein GNA3 in production of cell wall-degrading enzymes by Trichoderma reesei (Hypocrea jecorina) during mycoparasitism against Pythium ultimum," Biotechnology Letters, vol. 31, no. 4, pp. 531-536, 2009. 
[24] L. Li, S. J. Wright, S. Krystofova, G. Park, and K. A. Borkovich, "Heterotrimeric G protein signaling in filamentous fungi," Annual Review of Microbiology, vol. 61, pp. 423-452, 2007.

[25] J. E. Buss, S. M. Mumby, P. J. Casey, A. G. Gilman, and B. M. Sefton, "Myristoylated alpha subunits of guanine nucleotidebinding regulatory proteins," Proceedings of the National Academy of Sciences of the United States of America, vol. 84, no. 21, pp. 7493-7497, 1987.

[26] R. E. West Jr., J. Moss, M. Vaughan, T. Liu, and T. Y. Liu, "Pertussis toxin-catalyzed ADP-ribosylation of transducin. Cysteine 347 is the ADP-ribose acceptor site," The Journal of Biological Chemistry, vol. 260, no. 27, pp. 14428-14430, 1985.

[27] G. E. Turner and K. A. Borkovich, "Identification of a G protein $\alpha$ subunit from Neurospora crassa that is a member of the G(i) family," Journal of Biological Chemistry, vol. 268, no. 20, pp. 14805-14811, 1993.

[28] A. M. Kays and K. A. Borkovich, "Severe impairment of growth and differentiation in a Neurospora crassa mutant lacking all heterotrimeric $\mathrm{G} \alpha$ proteins," Genetics, vol. 166, no. 3, pp. 1229-1240, 2004.

[29] M. C. Lorenz and J. Heitman, "Yeast pseudohyphal growth is regulated by GPA2, a G protein $\alpha$ homolog," EMBO Journal, vol. 16, no. 23, pp. 7008-7018, 1997.

[30] E. Regenfelder, T. Spellig, A. Hartmann, S. Lauenstein, M. Bölker, and R. Kahmann, "G proteins in Ustilago maydis: transmission of multiple signals?" EMBO Journal, vol. 16, no. 8, pp. 1934-1942, 1997.

[31] A. Lafon, K.-H. Han, J.-A. Seo, J.-H. Yu, and C. d'Enfert, "Gprotein and cAMP-mediated signaling in aspergilli: a genomic perspective," Fungal Genetics and Biology, vol. 43, no. 7, pp. 490-502, 2006.

[32] S. Krystofova and K. A. Borkovich, "The heterotrimeric Gprotein subunits GNG-1 and GNB-1 form a G $\beta \gamma$ dimer required for normal female fertility, asexual development, and G $\alpha$ protein levels in Neurospora crassa," Eukaryotic Cell, vol. 4, no. 2, pp. 365-378, 2005.

[33] Q. Yang, S. I. Poole, and K. A. Borkovich, "A G-protein $\beta$ subunit required for sexual and vegetative development and maintenance of normal G $\alpha$ protein levels in Neurospora crassa," Eukaryotic Cell, vol. 1, no. 3, pp. 378-390, 2002.

[34] M. Versele, K. Lemaire, and J. M. Thevelein, "Sex and sugar in yeast: two distinct GPCR systems," EMBO Reports, vol. 2, no. 7, pp. 574-579, 2001.

[35] K. A. Borkovich, L. A. Alex, O. Yarden et al., "Lessons from the genome sequence of Neurospora crassa: tracing the path from genomic blueprint to multicellular organism," Microbiology and Molecular Biology Reviews, vol. 68, no. 1, pp. 1-108, 2004.

[36] R. D. Kulkarni, M. R. Thon, H. Pan, and R. A. Dean, "Novel Gprotein-coupled receptor-like proteins in the plant pathogenic fungus Magnaporthe grisea," Genome Biology, vol. 6, no. 3, article R24, 2005.

[37] T. M. DeZwaan, A. M. Carroll, B. Valent, and J. A. Sweigard, "Magnaporthe grisea Pth11p is a novel plasma membrane protein that mediates appressorium differentiation in response to inductive substrate cues," Plant Cell, vol. 11, no. 10, pp. 20132030, 1999.

[38] H. Zheng, L. Zhou, T. Dou et al., "Genome-wide prediction of $\mathrm{G}$ protein-coupled receptors in Verticillium spp," Fungal Biology, vol. 114, no. 4, pp. 359-368, 2010.

[39] E. M. Ross and T. M. Wilkie, "GTPase-activating proteins for heterotrimeric $\mathrm{G}$ proteins: regulators of $\mathrm{G}$ protein signaling (RGS) and RGS-like proteins," Annual Review of Biochemistry, vol. 69, pp. 795-827, 2000.
[40] M. Sato, J. B. Blumer, V. Simon, and S. M. Lanier, "Accessory proteins for G proteins: partners in signaling," Annual Review of Pharmacology and Toxicology, vol. 46, pp. 151-187, 2006.

[41] N. A. Lambert, C. A. Johnston, S. D. Cappell et al., "Regulators of G-protein signaling accelerate GPCR signaling kinetics and govern sensitivity solely by accelerating GTPase activity," Proceedings of the National Academy of Sciences of the United States of America, vol. 107, no. 15, pp. 7066-7071, 2010.

[42] D. R. Ballon, P. L. Flanary, D. P. Gladue, J. B. Konopka, H. G. Dohlman, and J. Thorner, "DEP-domain-mediated regulation of GPCR signaling responses," Cell, vol. 126, no. 6, pp. 10791093, 2006.

[43] M. Versele, J. H. de Winde, and J. M. Thevelein, "A novel regulator of $\mathrm{G}$ protein signalling in yeast, Rgs2, downregulates glucose-activation of the cAMP pathway through direct inhibition of Gpa2," EMBO Journal, vol. 18, no. 20, pp. 55775591, 1999.

[44] J.-H. Yu, J. Wieser, and T. H. Adams, "The Aspergillus FlbA RGS domain protein antagonizes $\mathrm{G}$ protein signaling to block proliferation and allow development," EMBO Journal, vol. 15, no. 19, pp. 5184-5190, 1996.

[45] K.-H. Han, J.-A. Seo, and J.-H. Yu, "A putative G proteincoupled receptor negatively controls sexual development in Aspergillus nidulans," Molecular Microbiology, vol. 51, no. 5, pp. 1333-1345, 2004.

[46] W. Fang, Y. Pei, and M. J. Bidochka, "A regulator of a G protein signalling (RGS) gene, cag8, from the insect-pathogenic fungus Metarhizium anisopliae is involved in conidiation virulence and hydrophobin synthesis," Microbiology, vol. 153, no. 4, pp. 1017-1025, 2007.

[47] H. Liu, A. Suresh, F. S. Willard, D. P. Siderovski, S. Lu, and N. I. Naqvi, "Rgs1 regulates multiple $\mathrm{G} \alpha$ subunits in Magnaporthe pathogenesis, asexual growth and thigmotropism," EMBO Journal, vol. 26, no. 3, pp. 690-700, 2007.

[48] G. C. Segers, J. C. Regier, and D. L. Nuss, "Evidence for a role of the regulator of G-protein signaling protein CPRGS-1 in $\mathrm{G} \alpha$ subunit CPG-1-mediated regulation of fungal virulence, conidiation, and hydrophobin synthesis in the chestnut blight fungus Cryphonectria parasitica," Eukaryotic Cell, vol. 3, no. 6, pp. 1454-1463, 2004.

[49] P. Wang, J. Cutler, J. King, and D. Palmer, "Mutation of the regulator of $\mathrm{G}$ protein signaling Crg1 increases virulence in Cryptococcus neoformans," Eukaryotic Cell, vol. 3, no. 4, pp. 1028-1035, 2004.

[50] C. Xue, Y.-P. Hsueh, L. Chen, and J. Heitman, "The RGS protein $\mathrm{Crg} 2$ regulates both pheromone and cAMP signalling in Cryptococcus neoformans," Molecular Microbiology, vol. 70, no. 2, pp. 379-395, 2008.

[51] S. Kasahara, P. Wang, and D. L. Nuss, "Identification of bdm-1, a gene involved in G protein $\beta$-subunit function and $\alpha$-subunit accumulation," Proceedings of the National Academy of Sciences of the United States of America, vol. 97, no. 1, pp. 412-417, 2000.

[52] J.-A. Seo and J.-H. Yu, "The phosducin-like protein PhnA is required for $\mathrm{G} \beta \gamma$-mediated signaling for vegetative growth, developmental control, and toxin biosynthesis in Aspergillus nidulans," Eukaryotic Cell, vol. 5, no. 2, pp. 400-410, 2006.

[53] J. A. Salamon, R. Acuña, and A. L. Dawe, "Phosphorylation of phosducin-like protein BDM-1 by protein kinase 2 (CK2) is required for virulence and $G \beta$ subunit stability in the fungal plant pathogen Cryphonectria parasitica," Molecular Microbiology, vol. 76, no. 4, pp. 848-860, 2010. 
[54] M. C. Overton and K. J. Blumer, "G-protein-coupled receptors function as oligomers in vivo," Current Biology, vol. 10, no. 6, pp. 341-344, 2000.

[55] C. Shi, M. F. Paige, J. Maley, and M. C. Loewen, "In vitro characterization of ligand-induced oligomerization of the S. cerevisiae G-protein coupled receptor, Ste2p," Biochimica et Biophysica Acta, vol. 1790, no. 1, pp. 1-7, 2009.

[56] K. A. Schandel and D. D. Jenness, "Direct evidence for ligandinduced internalization of the yeast $\alpha$-factor pheromone receptor," Molecular and Cellular Biology, vol. 14, no. 11, pp. 7245-7255, 1994.

[57] L. Chen and N. G. Davis, "Recycling of the yeast a-factor receptor," Journal of Cell Biology, vol. 151, no. 3, pp. 731-738, 2000.

[58] C. Davis, P. Dube, and J. B. Konopka, "Afrlp regulates the Saccharomyces cerevisiae $\alpha$-factor receptor by a mechanism that is distinct from receptor phosphorylation and endocytosis," Genetics, vol. 148, no. 2, pp. 625-635, 1998.

[59] D. M. Rivers and G. F. Sprague Jr., "Autocrine activation of the pheromone response pathway in mat $\alpha 2$ - cells is attenuated by SST2- and ASG7-dependent mechanisms," Molecular Genetics and Genomics, vol. 270, no. 3, pp. 225-233, 2003.

[60] N. Stoppacher, B. Reithner, M. Omann, S. Zeilinger, R. Krska, and R. Schuhmacher, "Profiling of trichorzianines in culture samples of Trichoderma atroviride by liquid chromatography/tandem mass spectrometry," Rapid Communications in Mass Spectrometry, vol. 21, no. 24, pp. 3963-3970, 2007.

[61] M. Schmoll, A. Schuster, R. D. N. Silva, and C. P. Kubicek, "The G-alpha protein GNA3 of Hypocrea jecorina (anamorph Trichoderma reesei) regulates cellulase gene expression in the presence of light," Eukaryotic Cell, vol. 8, no. 3, pp. 410-420, 2009.

[62] M. Komon-Zelazowska, T. Neuhof, R. Dieckmann et al., "Formation of atroviridin by Hypocrea atroviridis is conidiation associated and positively regulated by blue light and the $G$ protein GNA3," Eukaryotic Cell, vol. 6, no. 12, pp. 2332-2342, 2007.

[63] B. Reithner, R. Schuhmacher, N. Stoppacher, M. Pucher, K. Brunner, and S. Zeilinger, "Signaling via the Trichoderma atroviride mitogen-activated protein kinase Tmk1 differentially affects mycoparasitism and plant protection," Fungal Genetics and Biology, vol. 44, no. 11, pp. 1123-1133, 2007.

[64] K. Brunner, M. Omann, M. E. Pucher et al., "Trichoderma $G$ protein-coupled receptors: functional characterisation of a cAMP receptor-like protein from Trichoderma atroviride," Current Genetics, vol. 54, no. 6, pp. 283-299, 2008.

[65] M. Omann, S. Lehner, K. Brunner, et al., "A cAMP receptorlike GPCR is involved in Trichoderma atroviride mycoparasitism," in IOBC/WPRS Bulletin, pp. 105-108, IOBC/WPRS, 2009. 

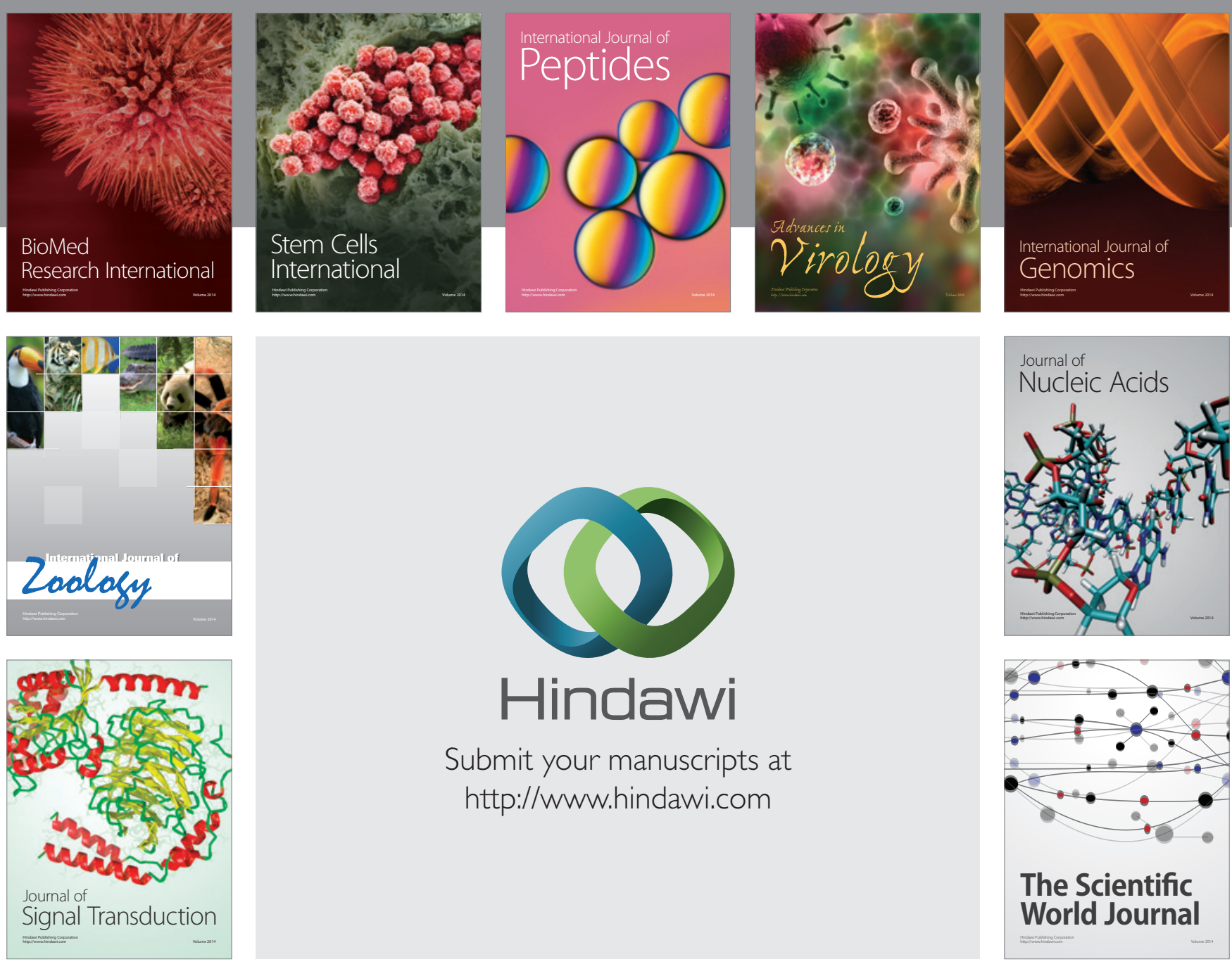

Submit your manuscripts at

http://www.hindawi.com
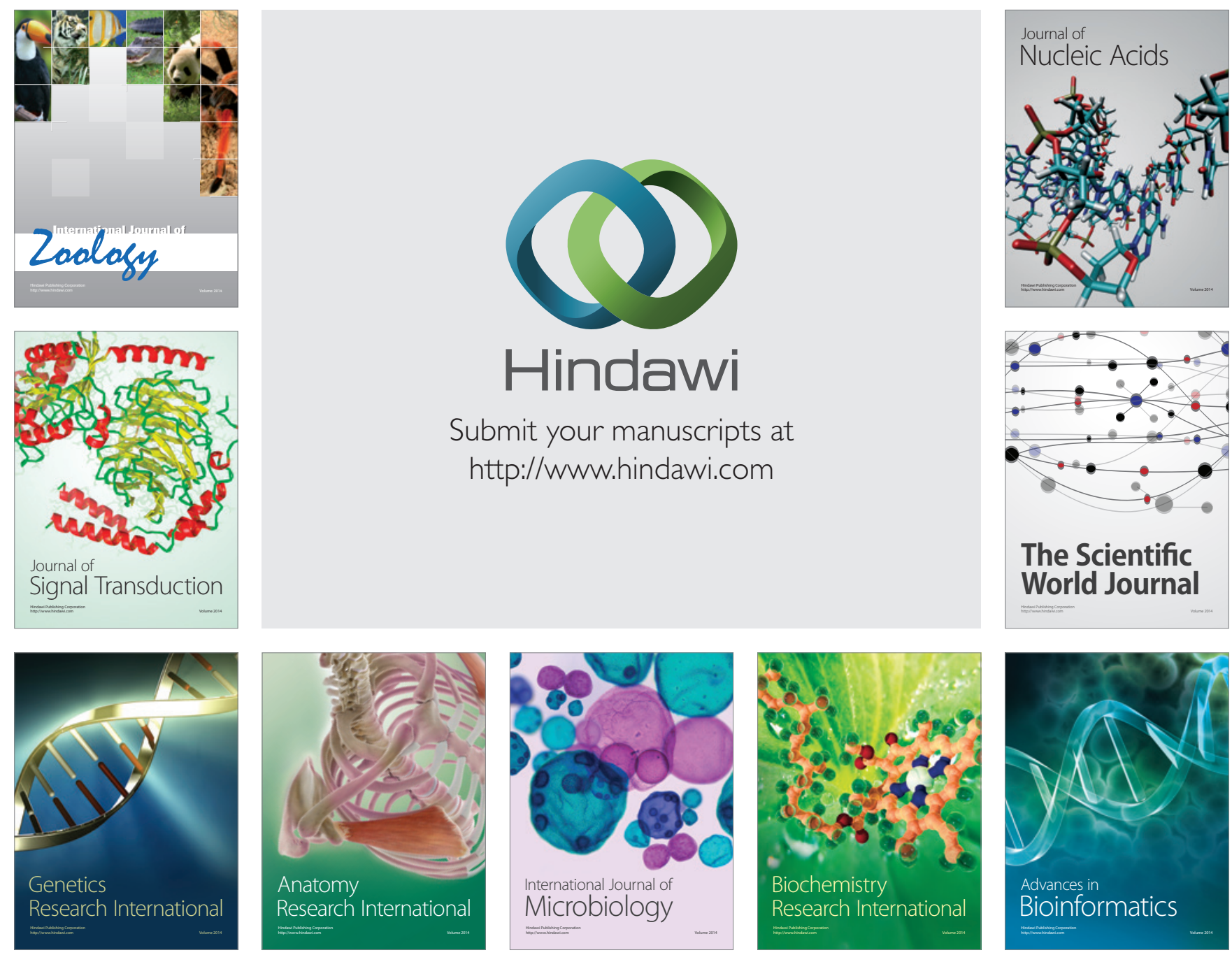

The Scientific World Journal
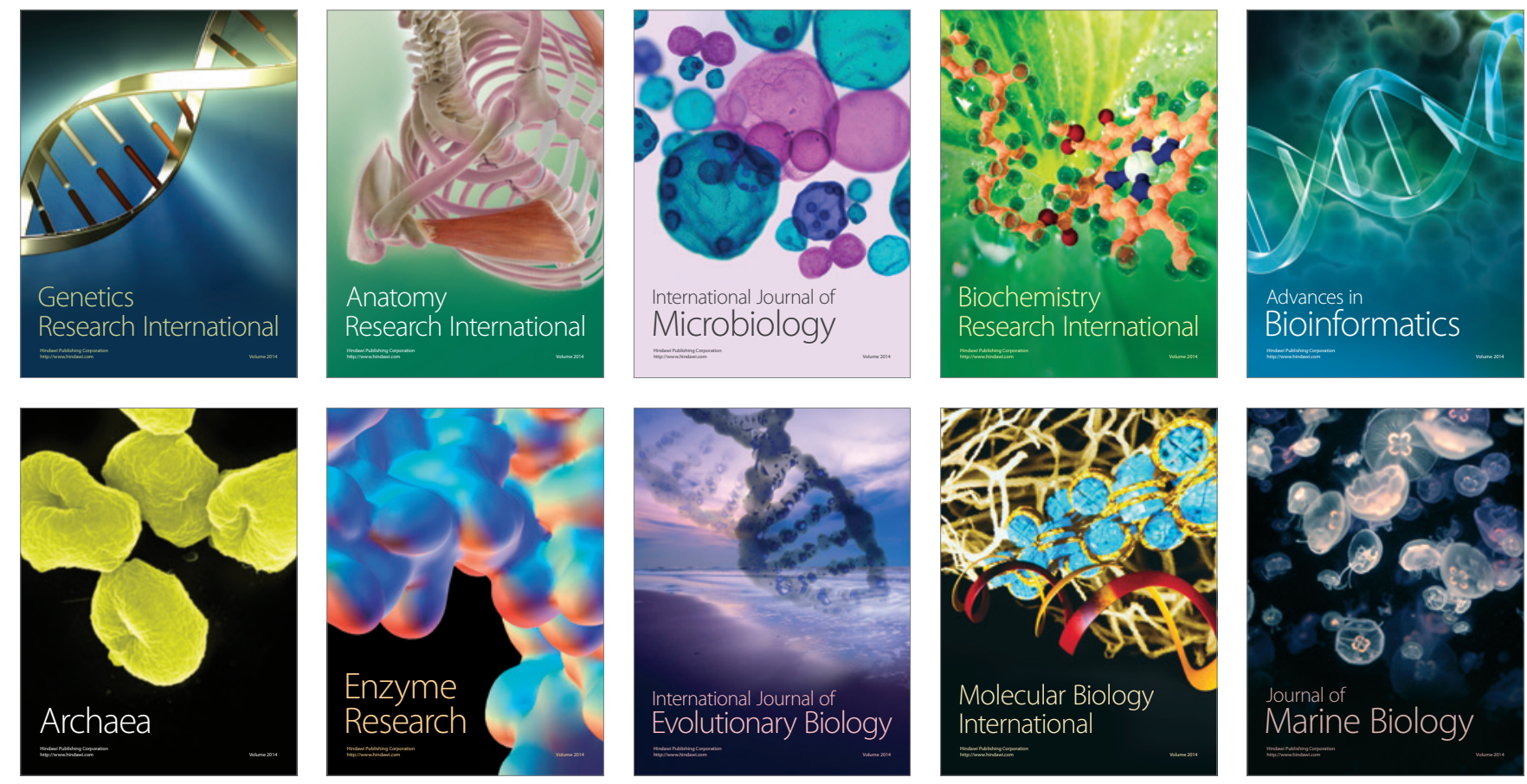